\title{
Sustainable Urban Revitalization Model- A Study through Formulating and Selecting the Planning Proposal
}

\author{
Md. Mustafizur Rahman1*, Francesco Lo Piccolo², \\ Giulia Bonafede ${ }^{2}$ \\ ${ }^{1}$ Department of Architecture, Shahjalal University of Science and Technology, Sylhet, Bangladesh \\ ${ }^{2}$ Department of Art, Architecture and Planning, University of Palermo, Palermo, Italy \\ Email: ^mustafiz.sust@gmail.com
}

How to cite this paper: Rahman, Md. M., Piccolo, F. L., \& Bonafede, G. (2020). Sustainable Urban Revitalization Model-A Study through Formulating and Selecting the Planning Proposal. Current Urban Studies, 8, 576-598.

https://doi.org/10.4236/cus.2020.84032

Received: August 27, 2020

Accepted: December 12, 2020

Published: December 15, 2020

Copyright $\odot 2020$ by author(s) and Scientific Research Publishing Inc. This work is licensed under the Creative Commons Attribution International License (CC BY 4.0).

http://creativecommons.org/licenses/by/4.0/

\begin{abstract}
The intent of this paper towards involvement of information lies about the analysis of the sustainable and revitalization methods around urban development and planning within Khulna city, Bangladesh; and proposed Boro Bazaar area and how it can be focused to a further sustainable urban neighborhood with a projected urban revitalization plan. Therefore the plan of this study is to recommend a contextual model through formulating of sustainable urban revitalization planning proposal of an urban area and next selecting a suitable strategy for their revitalization. To support this plan, present study first explains the background of the study; next, it explains the methodology, data collection process, afterwards formulating, selecting and evaluating techniques, which are essential for developing a contextual model for proposing sustainable urban revitalization strategy. Thus for a comprehensive consideration this present study has been progressed with a suitable evaluation plan for integrating and projecting the different factors playing significant role in the process of sustainable urban revitalization planning, i.e. physical, economics, social, environment, culture and overall networks within the study area. Based on the theories, principles, strategies and the different approaches, which have been employed for the overall city the critical recommendations at policy level, have been listed out, in a comprehensive and a systematic manner, to guide the sustainable urban revitalization planning for the proposed area.
\end{abstract}

\section{Keywords}

Sustainability, Revitalization, Model, Boro Bazaar 


\section{Background of the Study}

Owing to proper location and the accessibility of raw materials, Khulna city, Bangladesh; was developed as a middle level industrial city since 1950s. Because of these advantages, this city became a significant business hub with many big and small industries between 1950s and 1960s Khulna city was then a prominent business centre of the East Pakistan (before liberation) and main foreign currency earning sector which is established besides the two big rivers-Rupsha and Bhairab and successively this area was developed as a linier city around these rivers. However Khulna was announced as a metropolis in 1884 during British government and subsequently working like a recognized township. In that period city was depending highly on river based trade market (Reazul \& Alam, 2012). This trade market was developed around the several river ports that were locally named "Boro Bazaar" which means large market where trade activities were mostly distinguished by wholesale and retail shops (Rahman et al., 2019). Currently this central business hub and major economic district keeps up a significant amount of economic flow around the year (Dudek \& Houtte, 2008). This area also supplies equally direct and indirect services with skilled manpower and generates huge profit every year through several taxes; such as-land, port, shop and bazaar taxes. River ports around this area have been leased by the local government to export-import different goods within the country and the country side as well. In addition, this area is very significant because of several traffic links like-the proposed international highway between India and Bangladesh, the divisional highways, railways, inter district water ways passing through this region which creates it very prospective and key location to invest for all (Reazul \& Alam, 2012). Due to significant location and substantial economic flow, various urban development strategies were designed, although nowadays this area is one of the packed and unplanned areas throughout the history.

Although, urban development and planning approach is not new for Khulna city, but neither "sustainable urban design nor sustainable urban revitalization" nor any "comprehensive sustainable planning approach" has been deployed or experienced in this commercial city. The actions up to now have been limited to the mere planning, vision and target of an area or of relatively small sectors. It is under this present scenario that the present research endeavors to develop an understanding of "revitalization concepts" as a "special form of planning" and emphasizes both aspects the comprehensiveness of different approaches for dealing with the existing environments, and its accommodation for change and continuity of use in contemporary society. Consequently in the process of dealing with existing analysis as well as for developing new planning, many factors have to be considered, brought together, examined and projected with relation to each other. The study of elements in isolation at any stage results in failure in one way or the other, especially in existing situation. The study needs to bring 
the related elements or factors together to construct and comprehend the present situation, to analyze and highlight the critical problems, and to formulate proposals and/or suggestions according to the goals and objectives of the study set. For that, the study needs to develop a rational and appropriate model to bring all the related factors together at different stages of the planning process.

However, this paper will explain the process of configuration of the planning schemes through two steps; initially, an inclusive literature review within global scale has carried out with related concepts dealing among urban sustainability and revitalization. Secondly, a prearranged questionnaires survey has executed with experts and local people to evaluate the significance of city development and planning circumstance, to reach the definition of urban sustainability with a developed evaluation approach and ultimately to advocate for the reliability of the developed plan. In due course this process shows the proposed diagram with evaluation techniques that will illustrate a sustainable urban revitalization approach for the study area (Mosawi, 2017).

Therefore, this study is basically concerned with the question of sustainability and revitalization of mixed use commercial environment in order to accommodate the present and future needs of its inhabitants and to preserve and conserve its traditional fabric with its different values. As a result, different information's and approaches, from international, national and local levels, have been recognized are evaluated as well. Because both the urban sustainability and revitalization approaches have not been properly deployed or experienced in this area before, the study endeavors to develop understanding of urban sustainability and revitalization concepts and emphasizing not only on the development, but contemplates creative use and reuse of this mixed use commercial area and illustrates how these ideas are to accommodate the requirement and need of the contemporary society.

\section{Methodology and Data Collection Techniques}

The composition of the current research is survey based, field observation, questionnaire results analysis and evaluative. It investigates concepts for future urban revitalization and other contextual issues that manipulate the sustainable urban development process in the study area. Therefore both quantitative and qualitative approaches supported with the evaluative strategies were employed to conduct this research. Apparently, after illustrating the research approach the methods were comprised an initial literature review, analysis the theories of global and local perspectives which were followed by the local and expert participants through structured questionnaires survey. The source of these questions were specific to the individual being interviewed and aimed to produce results that directly addressed the past, present and future value of the study area. Subsequently to the elaboration of the theoretical framework, two different questionnaires survey-1) Local people (satisfaction level) and 2) expert participants (evaluation of planning proposals) were selected after a comprehensively reconsider 
of urban development planning across the Khulna city. Consequently following three types of methods were applied to collect the supplementary necessary data (Rahman et al., 2019):

1) Qualitative data through interviews with expert groups and local authorities;

2) Quantitative data through quick surveys and public questionnaires;

3) Select the study area.

\subsection{Interviews with Expert Groups and Local Authorities (Qualitative)}

Overall 13 nos. of experts (local authority) in different urban development areas were selected initially. Figure 1 shows the four processes and basis that experts were selected for interview and evaluations of the sustainable urban revitalization planning proposals (Table 4). Table 1 illustrates different group of selected expert participants along with their years of experiences in the field of urban development and planning issues within the Khulna city and proposed area.

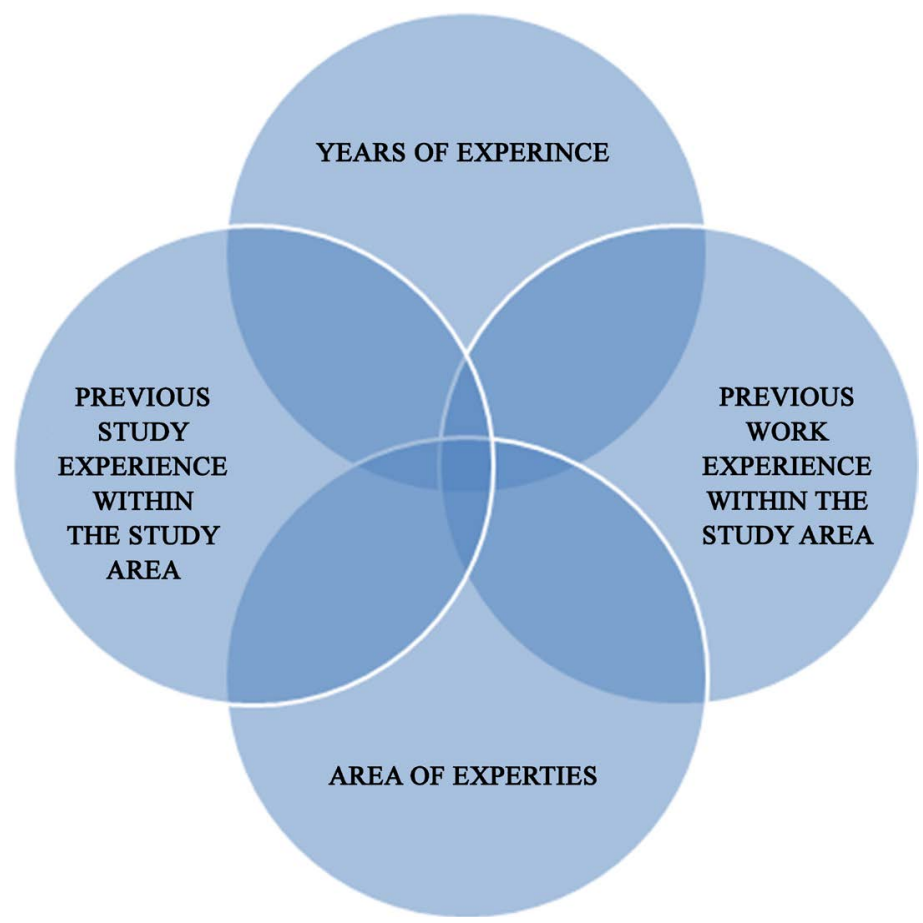

Figure 1. Method of selecting experts; Source: Rahman et al., 2019.

Table 1. Selection of expert participants for interviews; Source: Rahman et al., 2019.

\begin{tabular}{ccc}
\hline Group of expert participants & Total interviewed (person) & Years of experience \\
\hline Khulna City Corporation (KCC) & 2 & 18 \\
Khulna Development Authority (KDA) & 3 & 32 \\
Academic (KU, Urban Planner and Designer) & 5 & 21 \\
Local Consultant & 3 & 14 \\
\hline
\end{tabular}




\subsection{Quick Surveys and Public Questionnaires (Quantitative)}

Quick surveys and public questionnaires were used as a quantitative method and a primary tool through total 143 nos. of local residents and local business-owners. Among the 143 respondents, male respondents were highest in number and most of them were married and 30 years to 45 years of age. Two types of residents live in this study area-temporary (who has rentable house) and permanent (who has own house). The numbers of temporary residents were more than temporary residents and most of them were interrelated with business-owner who were 105 no in number. To determine the appropriate sample size, Fisher's formula was used. The researchers supposed a $99 \%$ desired level of confidence, which is equivalent to standardized normal deviate value of 2.58 and an acceptable margin of error of 5\% (standard value of 0.05 ). The collected data was then analyzed by SPSS25 software. In this step major themes were included: "perception of your neighborhood", "satisfaction with your neighborhood", "quality of life", and questions asking about residency and basic demographical profile such as-age, earnings and profession style within the study area (Figure 2). The development of the survey instrument was largely based upon analysis of questions that pertained directly to addressing these values while also utilizing a diverse series of academic literature. Questions were developed on a Likert scale with ranges such as "agree to disagree", or "satisfied to dissatisfied", to determine relative positive or negative attitudes toward specific subjects. In addition, interviews consisted as explained, before largely of meetings with planners, designers or other professionals involved with the government and private services. Although there was difficulty in obtaining interviews with a diverse range of involved stakeholders (particularly community-group leaders), the key interviewees provided significant feedback that ultimately helped to produce results.

\section{Formulation and Selection of Sustainable Revitalization Planning Proposal}

Contemporary Sustainable urban revitalization and planning considers the visions

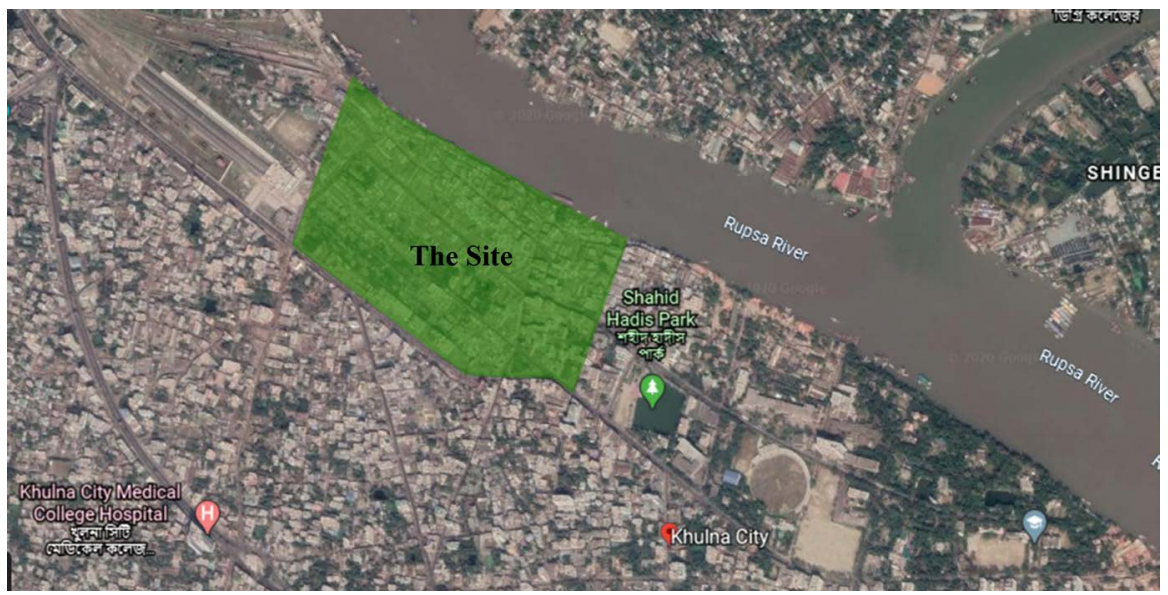

Figure 2. Study area. Source: Google Map. 
of development and strategies formulated with the involvement of main stakeholders in the context of understanding the existing urban neighborhoods, next to traditional formal urban plans, land use and regulatory instruments. On the other hand as sustainable urban revitalization desires to be distinct through the urban neighborhood-what local community's definite necessity? Thus it is very significant that the similar community as well agree on-what proposals are necessary in the planning process towards sustainable urban revitalization? Therefore, an urban community with local authority's through experts and local participant groups are necessary to develop a sustainable urban revitalization plan. Mean while, to formulate and select the planning proposal the study subsequently explains the next four steps for proposing a model as sustainable urban revitalization method:

1) Step 1: Principles and definitions of sustainable urban revitalization;

2) Step 2: Selection of planning principles;

3) Step 3: Construction of the planning proposals;

4) Step 4: Evaluation of the planning proposals.

\subsection{Step 1: Principles and Definitions of Sustainable Urban Revitalization}

To formulate the planning process this study requires selecting and identifying the principles and definitions of urban revitalization and urban sustainability. On the other hand in this step, local community should engaged on the planning process and recognize the final set of principles which are employing. Consequently, this study put up two (2) different but intra-related definitions and principles which are allied with the present learning that has been explained in the following.

\subsubsection{Urban Revitalization}

In 2009 Oktay and Hoskara explained that revitalization is a simple and uncompleted process of forming a concept of administration, which involves with the protection of significant urban neighborhoods that already has certain intangible values, such as-aesthetic value, architectural and environmental values, values as a part of cultural heritage, and the value of the continuity of the memory of citizens/communities. Again Ramlee et al., (2015) stated that usually in the revitalization process diverse terms were used in a way that can be exchanged. Then in 2010, Spandou et al., recognized this diverse terms in different ways, such as-Regeneration, Renewal, Redevelopment, Rehabilitation, Conservation, Restoration, Reconstruction, Refurbishment, Renaissance. On the other hand in 2014, Vileniske \& Urbonas explained that process and language of revitalization is able to involve with physical and social, cultural and economic dimensions. Revitalization concept can create stability within present urban development and planning by protecting urban context, customs, practice and individuality.

Furthermore, Jagxhiu \& Kovács-Andor, 2018 stated that through revitaliza- 
tion project urban community can increase income by generating occupation prospect, conserve natural possessions, provides suitable urban services and facilities for the user. By referring to the term of regeneration, it also deals with issues similar to revitalization. According to Ntshona in 2013, regeneration assists to address various urban questions such as-economic limitation, joblessness, social deficiency and prohibition, spoiled land and environmental contamination. It is also a wise move in considering the urban sustainable development and regeneration as well as given rejuvenate and should be fully utilized. In addition, conservation commonly uses for revitalization. Samadi et al., (2012: p. $71)$, state that "conservation is considered as the most commonly practiced approach to most heritage development. Yet again in 2012 Baroldin \& Din shows that conservation is a physical interference in the fabric of the building to ensure its continued performance as well. The heritage revitalization arises from the issues of generalization due to globalization in the early decade of the millennium".

Globally, few researches have been carried out various researches in relation to the urban revitalization. In 2010, Spandou et al. stated that as a method urban revitalization consist of a set of urban management strategies to improve economic, social, environmental, cultural and historical redevelopment of challenging, disadvantaged and abandoned urban areas. Based on urban revitalization process, the targets to be achieved is to rebuild the city in which people work and live with good environmental quality; adequate social, cultural and recreational facilities. Therefore actions and strategies had taken to address the problems in urban areas, especially restructuring urban economic, social reaction and rehabilitation the environmental destruction. So, physical activities will help to improve the quality of life and creating sustainable communities.

\subsubsection{Sustainability and Urban Revitalization}

Again Oktay \& Hoskara in 2007 assumed that if the urban revitalization process is applied to the abovementioned three systems-physical, economic and social, afterwards an unique sustainable historic environments will create; in this way sustainable urban neighborhoods can be produced with the help of urban revitalization as well. Since this statement it is also believed that sustainable community has the similar kind of schemes-economy, environment and society. In 1996, Bauen et al. described that a sustainable community have to find out and studying latest methods of making economic vitality, maintaining a healthy environment and building healthy communities and meeting local needs. Yet again Oktay \& Hoskara, in 2007 described that through sustainable program a strong urban community can be produced by improving and adapting the economic, social and physical environments of cities in order to achieve the required international standards of the urbanization process. In particular, now and again significant urban areas may go down its economic feasibility and by this go down again it may results decompose in the urban community and finally in urban fabric and create social segregation due to the rapid urbanization. Oktay 
\& Hoskara (2007) again supposed that sustainable urban revitalization should included-preserving and carrying the social, economic and physical structure for future with dealing with social equity, environmental preservation and economic development.

Therefore, "sustainability and revitalization"- the two different theory, are related and directly associated within every urban community program. Based on this relationship, Oktay \& Hoskara, 2007 explained this process should involve within the followings:

- Sustainable physical revitalization: Introducing sustainable physical revitalization means to improve the physical/environmental sustainability and address issues related to making minimum use of renewable and non-renewable resources, recycling of resources, protect and enhance the built environment, safeguard historic buildings, attend to the redevelopment of abandoned open areas, enhance the landscape and provide green spaces in historic urban areas.

- Sustainable economic revitalization: Planning to sustainable economic revitalization implies to lead to economic sustainability (competitiveness) that is related with meeting the human needs and improving the living conditions. This revitalization process addresses the issues that are related to mixed land uses, tourism and high-income people with job opportunities.

- Sustainable socio-cultural revitalization: Sustainable socio-cultural revitalization involves guiding to social sustainability/equity or social unity and it tackle social equality, justice and freedom.

\subsection{Step 2: Selection of Planning Issues}

Later than an agreement has made concerning the values and descriptions of sustainable urban revitalization, $2^{\text {nd }}$ stage of the study proposed "the selection of the planning principles or components" of sustainable urban revitalization within a specific neighborhood. Since there are several critical questions that can applicable to any community such as-physical, social with economic stipulation of the specific area. In this $2^{\text {nd }}$ step, the present research also revealed that the planning principles within a specific neighborhood have to comprise with existing situations, challenges and problems besides that critical questions.

However, the process again described through a literature review to conclude with international issues which are identical with existing conditions and previous planning performances through public participation. Consequently, the study has been produced the following "concluding set of selected planning issues" (Table 2) by assessing four several global concerns-1) Main issues of Sustainable City 2) Scholarly works and articles 3) The Associated Global Agreement and 4) The guidance of European Union (EU) on sustainable urban revitalization, urban regeneration, and urban rehabilitation (2004) and proposes for the sustainable urban revitalization issues in terms of planning results and planning developments. 
Md. M. Rahman et al.

Table 2. Concluding set of selected planning issues; Source: Author, 2019.

\begin{tabular}{|c|c|c|}
\hline \multicolumn{2}{|l|}{ Field of Issues } & \multirow{2}{*}{$\begin{array}{l}\text { Proposed Selected Planning issues for Urban Revitalization Projects } \\
\text { 1. Assessing and categories the resources of the area-physical, economic, social and cultural }\end{array}$} \\
\hline \multirow[t]{21}{*}{ Planning Results } & Physical Planning & \\
\hline & & 2. Livelihood standards within the built environment should enhanced \\
\hline & & 3. Endorsing and incorporating tradition and conserve the resources of the area \\
\hline & & 4. Recovering Livelihood and housing standards for low income groups \\
\hline & & 5. Stimulate and renovate urban plan and design \\
\hline & & 6. Increasing public awareness on contextual issues \\
\hline & Economic Planning & 1. Economic prospective of the area should utilized \\
\hline & & a) Native profitable and multi-functional economic actions should developed \\
\hline & & b) Left over lands and historical building should conserved \\
\hline & & c) Educating and training of unskillful employees inside the area \\
\hline & & 2. Generate new job with native profitable economic sectors \\
\hline & & 3. Promoting funds, stimulating investment with safe and secured places for all \\
\hline & & 4. Increasing land values and reducing vacancy levels of land \\
\hline & & 5. Control land tenure ship for community constancy \\
\hline & Social Planning & 1. Taking into account of social ties, justice and neighborhood-social structure \\
\hline & & - Privilege to minority for entrance within fundamental services \\
\hline & & - Social interaction with business men and local residents by creating more social activities \\
\hline & & $\begin{array}{l}\text { 2. Improving slum area by education and employment opportunities and respecting livelihood } \\
\text { approach for all }\end{array}$ \\
\hline & & 3. Conserve and preserve social and cultural uniqueness \\
\hline & & $\begin{array}{l}\text { 4. Enhancing the accessibility opportunities within—offices, schools, colleges, hospitals and } \\
\text { prayer spaces }\end{array}$ \\
\hline & & 5. Controlling transfer rate from rural to urban area \\
\hline \multirow{6}{*}{\multicolumn{2}{|c|}{ Planning Developments }} & 1. Build up a contextual planning with suitable authorized appliances \\
\hline & & 2 Increase knowledge to access the planning approach \\
\hline & & 3. Progressive assessment making process with public participations and awareness \\
\hline & & 4. Develop appropriate coordination with all public authorities \\
\hline & & 5. Develop a committed and skilled team with supplementary technical support \\
\hline & & 6. Consider the target, budget and time of the planning process \\
\hline
\end{tabular}

\subsection{Step 3: Construction of the Planning Proposals}

After the appropriate issues have been recognized and put into the form of an enquiry, step 3 of the study proposed a precise way to answer those questions regarding physical, economic and social sustainable revitalization planning proposal within the present study area. However, these planning proposals could previously explain in the study or could hire or modified present questioning techniques for the purpose of answering sustainable issues. According to many researchers if the planning issues are not eagerly accessible then fresh planning proposals might be needed to be created. Consequently, the study once again constructed the following planning proposals through questioning the selected expert participants which have been described in Table 3. 
Table 3. Construction of the planning proposals. Source: Author, 2019.

\begin{tabular}{|c|c|c|c|}
\hline \multicolumn{2}{|c|}{ Field of Issues } & \multirow{3}{*}{$\begin{array}{l}\text { Questions (considering sustainable planning) } \\
\text { 1. Is the present physical and environmental } \\
\text { planning sustainable? }\end{array}$} & \multirow{2}{*}{$\begin{array}{l}\text { Planning proposals (within the study area) } \\
\text { 1. Riverside development and its physical condition }\end{array}$} \\
\hline Planning & Physical & & \\
\hline \multirow{12}{*}{ Proposals } & Planning & & 2. Drainage systems and Noise pollutions with the aim of \\
\hline & & 2. Is this present planning considering context? & improving its efficiency and facilities \\
\hline & & 3. Is local physical planning attracting visitors? & 3. Condition of community services like-waste management \\
\hline & & 4. Is there any illegal built form? & and sewage \\
\hline & & 5. Are all roads connected to each other within & 4. Road network, transportation systems and level of service \\
\hline & & this area? & $\begin{array}{l}\text { 5. Condition of shades or resting places for public transport and } \\
\text { its administration }\end{array}$ \\
\hline & Economic & 1. Is the present economic planning healthy and & 1. Employment and unemployment condition \\
\hline & Planning & considering sustainability issue? & 2. Shopping environment, facilities and services \\
\hline & & $\begin{array}{l}\text { 2. Is present economic condition helpful for } \\
\text { urbanity and businessmen? }\end{array}$ & $\begin{array}{l}\text { 3. Continued boost in the economic standard of living within } \\
\text { the study area, with the aim of balanced growth and stability }\end{array}$ \\
\hline & Social Planning & 1. Is the present community healthy socially? & 1. Accessibility towards public services \\
\hline & & 2. Is this community considering accessibility & 2. Open spaces and recreation facilities \\
\hline & & and open spaces as a social interaction? & $\begin{array}{l}\text { 3. Ensuring equal access and balance investment among all the } \\
\text { neighborhood }\end{array}$ \\
\hline
\end{tabular}

\subsection{Step 4: Evaluation of the Planning Proposals}

Although for accomplishing urban sustainable revitalization there are several planning methods with assessments and evaluation techniques, therefore the evaluation process of this study comprises several steps with a number of techniques. As a result of this step-evaluation of the planning proposals will be described and summarized in additional information. This paper therefore proposes an integrated evaluation process through a thorough understanding and final planning proposals of the study area by setting up an interview yet again with the same selected experts group. Though there are three main objectives of sustainable urban revitalization planning-physical, economic and social planning proposal within the study area, so this paper proposes to analyze and finalize a framework to achieve these objectives. Consequently for evaluation method, study considered the three main possessions as the final planning proposals: improving the physical environment; promoting economic vitality; and promoting social conditions. However, to evaluate planning proposals this paper has been process two types of consideration- "consideration 1" and "consideration 2"; were scheduled through the selected experts group and local participants.

The experts group from-KCC (Khulna City Corporation), KDA (Khulna Development Authority), AC (Academician) and LC (Local Consultant) was selected to split their planning proposals concerning the study area which was scheduled in the "consideration 1" row (Table 4).

In this step local participants were not directly requested to join the evaluation process, hence preceding survey results from the local participants were considered only as an evaluation technique. Subsequently this evaluation method 
planned to local participant's concerns ("consideration 2"; Table 4; satisfactions about present situations and selected 9 different sustainable issues-Drainage systems, Air and Noise pollution, Transportation systems, Width of Road and Side walk, River side development, Employment and job environment, Shopping Facilities and Environments, Accessibility towards Public services and Open spaces and recreation facilities) named as "occupation" group-DM (Daily Market), GM (Garments), HW (House Wife), SE (Service), SV (Street Vendor), ST (Student) and WS (Wholesale) was selected to explicate their proposals regarding the study area.

In the following a more specific planning with proposals has been recognized for evaluating the guidelines efficiency of sustainable urban revitalization within the proposed area. The results from both the in-depth interviews (experts) and survey-based interviews (local people), as well as the results from the survey will then be consider against these effects (Table 4).

\subsubsection{Physical Revitalization and Sustainable Planning Proposal within the Study Area}

In the "consideration 1" the evaluation method (Table 4) has selected the following seven different issues by the researchers from the final set of criteria (Table 2) and construction of the planning proposals (Table 3). Then the experts group (KCC, KDA, AC, and $\mathrm{LC}$ ) has joined to put their individual views as sustainable physical revitalization planning proposals within the study area:

1) Assessing and categories the resources of the area-physical, economic, social and cultural;

2) Livelihood standards within the built environment should enhanced;

3) Recovering urban network and public services with existing situations;

4) Revitalizing urban design through river side and road network, side walk development;

5) Introducing comprehensive and community breathing space;

6) Improving the accessibility providing public traffic and good side walk links;

7) Endorsing with incorporating tradition and conserve the resources of the area.

Again in the "consideration 2" the evaluation method (Table 4) has selected five different issues and sustainable physical revitalization planning proposals for-transportation facilities, river side area, road/pedestrian, pollutions and drainage systems within the study area by the both local. The local participants ("occupation" group) explained their satisfaction regarding present situations which are listed in the evaluation 2 method (Table 4). The statistical information of five different issues has been explained in Appendix 1 and Table A1.

\subsubsection{Economic Revitalization and Sustainable Planning Proposal within the Study Area}

In the sustainable economic planning proposal process, five proposals (Concluding set of selected planning issues, Table 2 and construction of the planning proposals, Table 3) have been set in the "consideration 1" by the study which 
was evaluated by the expert's participants for sustainable economic revitalization planning within the study area. These were:

1) Economic prospective of the area should utilized;

a) Native profitable and multi-functional economic actions should developed;

b) Left over lands and historical building should conserved;

c) Educating and training of unskillful employees inside the area.

2) Generate new job with native profitable economic sectors;

3) Promoting funds, stimulating investment with safe and secured places for all;

4) Reducing open land by increasing land values;

5) Control land tenure ship for community constancy.

Once more local participants also explained their views about two altered issues-employment area and shopping facilities which has been listed in the "consider 2" (evaluation 2, "occupation" group) line for sustainable economic revitalization within the study area. Then the statistical information of two altered issues has been explained in Appendix 2 and Table A2.

\subsubsection{Social Revitalization and Sustainable Planning Proposal within the Study Area}

In terms of achieving sustainable social revitalization inside the study area there were following five (concluding set of principles, Table 2 and construction of the planning proposals, Table 3) planning proposals considered by the researchers and then evaluated by the expert's participants:

1) Taking into account of social ties, justice and neighborhood-social structure;

- Privilege to minority for entrance within fundamental services;

- Social interaction with business men and local residents by creating more social activities.

2) Improving slum area by education and employment opportunities and respecting livelihood approach for all;

3) Conserve and preserve social and cultural uniqueness;

a) Enhancing the accessibility opportunities within-offices, schools, colleges, hospitals and prayer spaces;

b) Controlling transfer rate from rural to urban area.

Once more from the field survey, the local respondents explain two different issues as their proposal for planning of social sustainability with the study area:

1) Accessibility towards Public services;

2) Open spaces and Recreation facilities.

In addition, the statistical information of these two different issues has been explained in Appendix 3 and Table A3.

\section{Evaluation Results of the Sustainable Urban Revitalization Planning Proposals}

A total of sixteen sustainable urban revitalization planning proposals are evaluated, examined and compared in Table 4 by the selected experts group. Significantly, 
Table 4. Evaluations of the sustainable urban revitalization planning proposals.

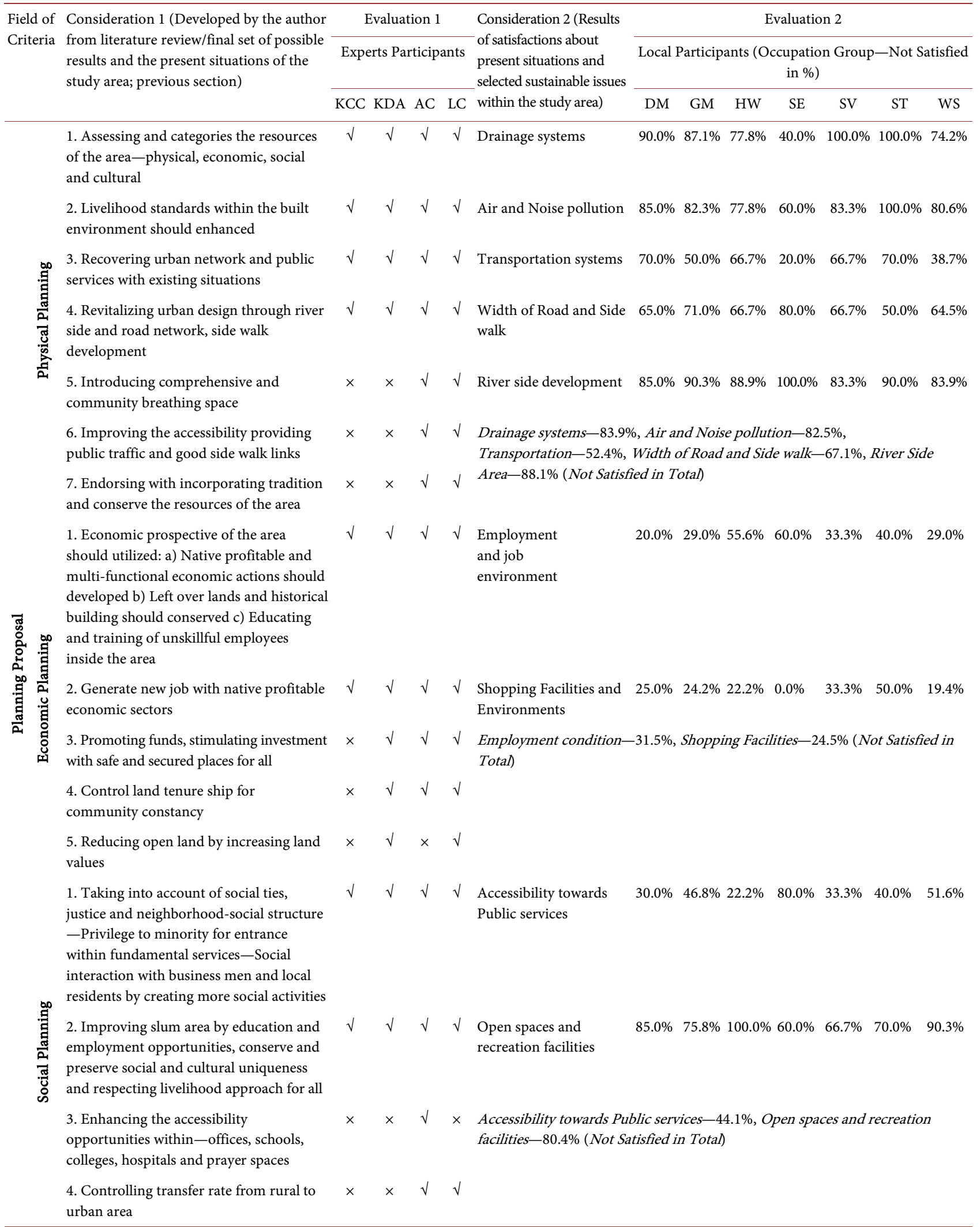

The evaluation results suggest by the Experts: $(\sqrt{ })$ Agreed; $(x)$ Not Agreed. 
eight of the planning proposals by the study are considered and agreed by all four respondent experts group. These include four out of seven of the physical planning proposals, two of five economic planning proposals and two of four social planning proposals. Three of the economic planning proposals and two of the social planning proposals are not fully agreed by the respondent groups for financial and political reasons. Considerably, the physical planning proposals for "introducing comprehensive and community breathing space, improving the accessibility providing public traffic and good side walk links and Promoting and integrating heritage conservation in modern life" is considered to have been unsuccessful by both KCC and KDA expert's respondent again for the financial and political reasons.

Subsequently, the evaluation results shows that the planning proposals related to the sustainable urban revitalization within the study area has been certainly considered and agreed by selected expert groups. When evaluating the respondent (experts group) answers in the matrix of planning proposals in the next Table 4, it is apparent to the revitalization plan within the Boro Bazaar area can be considered as reasonably effective for the future urban development and planning. In addition, based on this analysis, the selected experts group explained that the planning proposals within this area concerning to social and economic revitalization materialize can be accomplished more methodically after those for the physical revitalization planning proposals have been developed accordingly and taking into account of the planning proposals.

\section{Developing a Model for Proposing Sustainable Urban Revitalization Strategy}

This study assume that in order to proposing a sustainable urban revitalization model by analyzing the existing situations, problems, challenges and difficulties, the primary action is to describe neighborhood approach, urban sustainability, revitalization and among their connection. This could also be used as the proposals to study the efficiency of the urban model. According to Badescu, S. et al., (2009), on urban revitalization in his evaluation revision-in an evaluation analysis the results of good exercise of urban revitalization could be used as the planning proposals. On the other hand Cabe \& Detr (2001) described that to establish a model, a study can prefer the statistics uses in the preceding successful urban design program to presentation of new urban design applications. However, it is apparent that globally there is no previous specific model which could be precisely intended for proposing the final illustration or strategy within this part. Therefore, in the following this paper will recommend a model through formulating of planning proposals and then selecting a suitable plan for sustainable urban revitalization program.

\section{The Model}

Supporting the principles, definitions and on the association with urban sustai- 
nability and revitalization, the possible planning of urban revitalization and the possible planning of its sustainability require to be determined in order to accomplish the sustainable urban revitalization program that will guide the study to propose the planning which has been described in the following proposed model (Figure 3). Since it can be seen from the above several discussions that proposed model in general terms will comprise with the next four consistent stages:

1) The first stage is to identification of the probable planning strategy of revitalization through physical, economic and social dimensions of the area. These dimensions are selected through global principles and definitions and urban revitalization examples as of diverse countries with the relations and concerns of the existing local community. Then it includes the tangible time period to be completed the stage-short time strategy and longtime strategy.

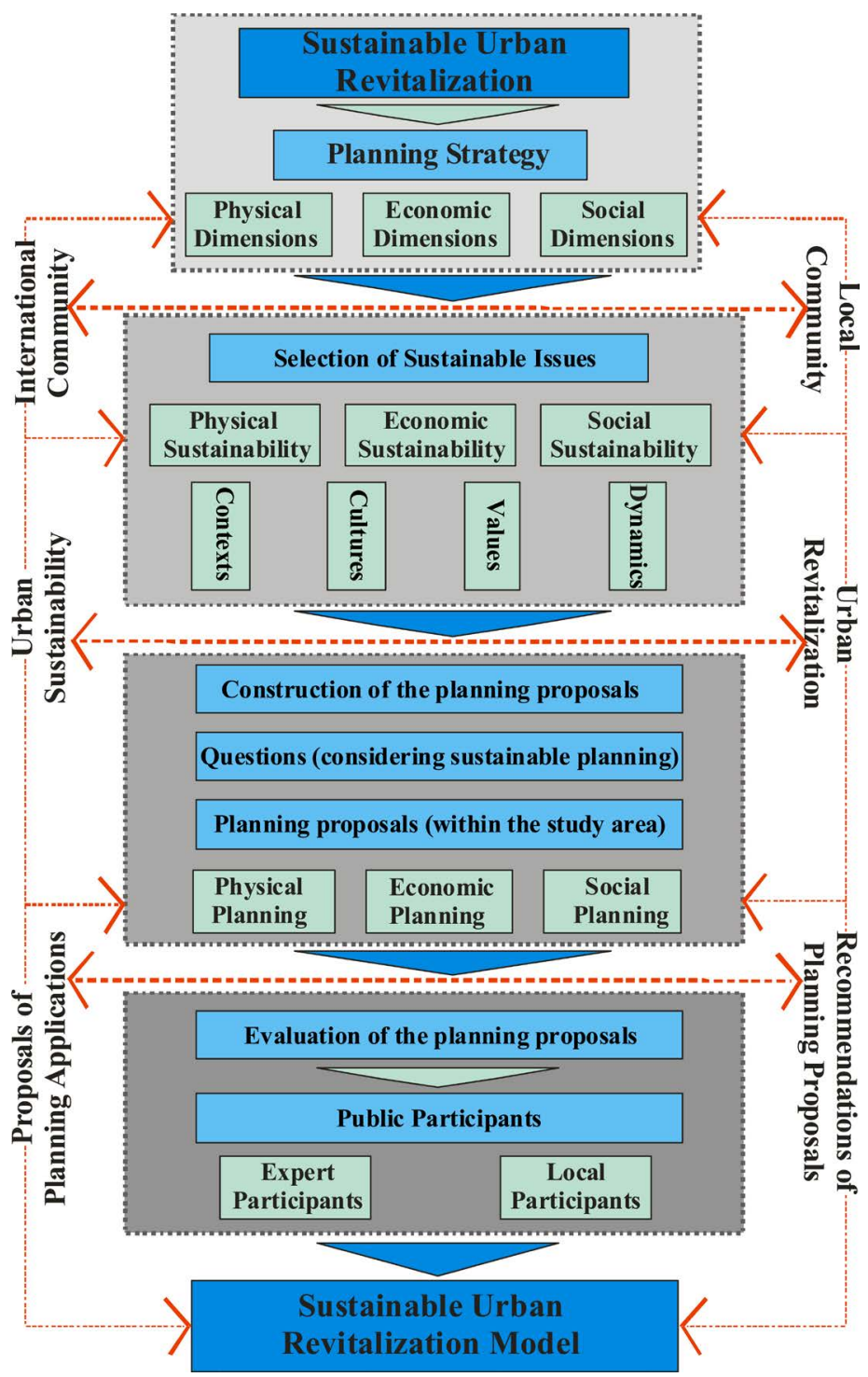

Figure 3. Proposed model for sustainable urban revitalization within the study area. 
2) This stage has been designed among the dimensions of sustainability with the help of selection of sustainable issues. The appropriate, assessable and available physical, economic and social issues of sustainability are selected with dynamics/values and cultures/contexts of the area. However, if requires several existing issues has also been taken into consideration for planning this stage.

3) The next step has been corresponded the final set of feasible planning of urban revitalization proposals and sustainability issues in order to construct a suitable planning proposal of sustainable urban revitalization.

4) Every appropriate planning proposal from selections, constructions, and concluding set of planning principles under the dimensions of urban sustainability and revitalization (physical, economic and social conditions) has been separately grouped under the broad issues of proposed model and finally it has been evaluated by the experts and local communities through open participations.

\section{Conclusion}

Concerning sustainable development of physical, economic and social planning this was generally viewed as been somewhat unsuccessful and unplanned within the study area. Thus this paper is to address the stages that follow the present study for proposing planning proposals and a proposed model of sustainable urban revitalization project execution phase within the study area. However, this study and the proposed planning proposals with proposed model have been connected with the two ideas; "urban sustainability and revitalization strategy" inside the "physical, economic and social dimensions" within significant urban areas in order to formulate it more appropriate. As it was found, successful urban revitalization can be accomplished through applying the most applicable planning approach. Again previous to apply the most applicable planning approach, the stage of sustainability should be recognized as well. Although it cannot be confirmed that the planning proposals and evaluation process described above are inclusive, though this framework could offer authentic and positive approach to the urban planner and their outlook in the direction of this theme.

Furthermore, this research was conducted in the context of Khulna city, Bangladesh and proposed area as an attempt to explore how an urban neighborhood can meet the sustainable development and its objective through this planning to facilitate the neighboring development projects with relation towards the international style to urban sustainability. The proposed planning and model would also create an answer for the urban planner and local authority those who would like to work with comparable projects in the future. To inspect if the urban revitalization and sustainability stand apart within the Khulna city context, the study tried to develop a useful, methodical and consistent dimension instrument. Towards the end of the study, it has been believed that the process analysis and the projected sustainable urban revitalization model will guide development future 
policy which could be an integral part of the sustainable urban revitalization planning and implementation process for the study area. Consequently, the proposed developed model for "sustainable urban revitalization" can be used either for assortment of the most suitable urban revitalization planning proposal or for evaluation of the urban revitalization scheme before or after execution.

In addition, to propose a sustainable urban revitalization model following two points should be taken into account:

1) When collecting the relevant statistics, the possibilities of limitations of the present resources of the research.

2) When conducting the survey, the possibilities of understanding of the participants about the proposed study area.

Due to these, it is difficult to build up an appropriate "sustainable urban revitalization" model which can cover a wide range of planning scheme and its consequent considerations. As a result, the relevant physical, economic and social planning proposals for the local context at this stage were included, and a reasonable and manageable amount of planning proposals was finally selected.

\section{Conflicts of Interest}

The authors declare no conflicts of interest regarding the publication of this paper.

\section{References}

Badescu, S. et al. (2009). Sustainable Urban Development through the Empowering of Local Communities. In Sustainable Development-Policy and Urban Development-Tourism, Life Science, Management and Environment (pp. 41-66). London: IntechOpen.

Baroldin, M., \& Din, S. A. M. (2012). Documentation and Conservation Guidelines of Melaka Heritage Shophouses. Procedia-Social and Behavioral Sciences, 50, 192-203. https://doi.org/10.1016/j.sbspro.2012.08.027

Cabe, \& Detr (2001). The Value of Urban Design, Commission for Architecture and the Built Environment.

Dudek, P., \& Houtte, E. V. (2008). The Riverfront of Khulna (Bangladesh), a Designerly Investigation. Master's Thesis, Heverlee: Department of Architecture, Urbanism and Planning (ASRO).

Jagxhiu, B., \& Kovács-Andor, K. (2018). Prizren-Revitalizing the Historic Water Channel System for Modern City Life. Pollack Periodica, 13, 157-168. https://doi.org/10.1556/606.2018.13.1.14

Mosawi, A. Q. (2017). Towards Sustainable Urban Design Strategies for Historic City Centres in Iraq. Development of an Assessment Approach for Urban Regeneration Projects. Dortmund: Dortmund University.

Ntshona, N. (2013). The Role of the City Development Agencies in the Urban Regeneration of the Inner City of Johannesburg. A Research Report, Johannesburg: The Faculty of Engineering and the Built Environment, University of the Witwatersrand.

Oktay, B., \& Hoskara, S. (2007). Measuring the Sustainability Level of the Walled City of Famagusta in Northern Cyprus. Conference: EDRA 38: Building Sustainable Communities, Sacramento, 30-3 May-June 2007, 269. 
Oktay, B., \& Hoskara, S. (2009). A Model for Measuring the Sustainability Level of Historic Urban Quarters. Journal of European Planning Studies, 17, 715-739. https://doi.org/10.1080/09654310902778201

Rahman, M., Piccolo, F., \& Bonafede, G. (2019). Sustainable Urban Revitalization within a Historical Urban Neighborhood-A Useful Approach to Complete. Journal of Advanced Research in Construction and Urban Architecture, 4, 35-53.

Ramlee, M., Omar, D., Samadi, Z., \& Yunus, M. (2015). Revitalization of Urban Public Spaces: An Overview. Procedia-Social and Behavioral Sciences, 201, 360-367. https://doi.org/10.1016/j.sbspro.2015.08.187

Reazul, M., \& Alam, A. (2012). Urban Regeneration for Sustainable Economic Growth: The Study of Boro Bazaar in Khulna, Bangladesh. Journal of Social and Development Sciences, AMH International, 3, 111-122. https://doi.org/10.22610/jsds.v3i4.693

Samadi, Z., Camila, C., \& Macario, R. (2012). Urban Revitalization and Transport: Local Factors and Driving Forces from a Stakeholders View. Conference: 3rd Annual Conference on Planning Research CITTA, Lisbon, Portugal, December 2010, 1-22.

Vileniske, I., \& Urbonas, V. (2014). Urban Regeneration in the Context of Post-Soviet Transformation: Lithuanian Experience. Journal of Cultural Heritage, 15, 637-643. https://doi.org/10.1016/j.culher.2014.01.002 


\section{Appendix 1}

Table A1. Statistical information of Occupation \& Transportation with physical facilities.

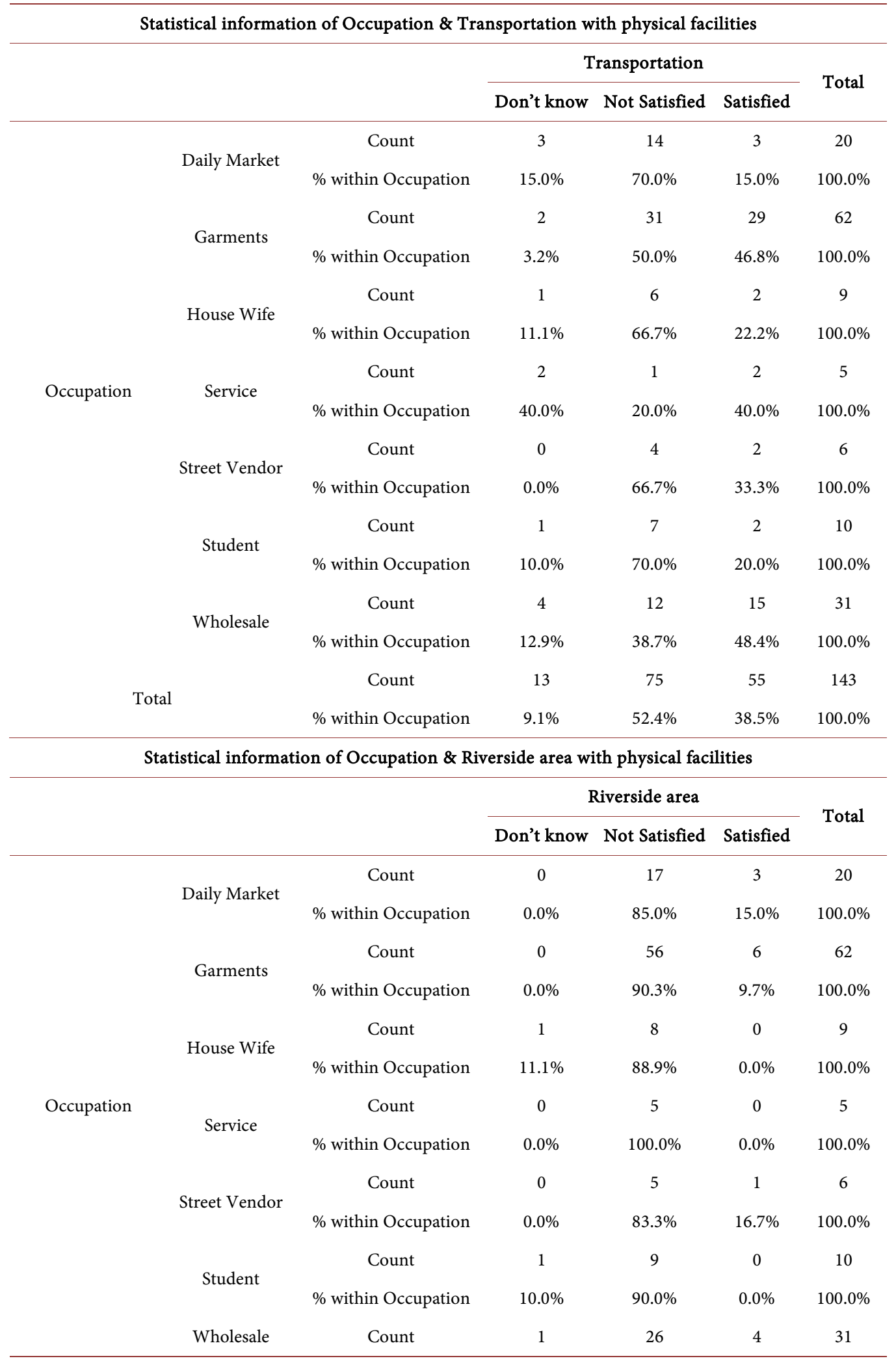


Md. M. Rahman et al.

\section{Continued}

\begin{tabular}{|c|c|c|c|c|c|c|}
\hline & & $\%$ within Occupation & $3.2 \%$ & $83.9 \%$ & $12.9 \%$ & $100.0 \%$ \\
\hline \multirow{2}{*}{\multicolumn{2}{|c|}{ Total }} & Count & 3 & 126 & 14 & 143 \\
\hline & & $\%$ within Occupation & $2.1 \%$ & $88.1 \%$ & $9.8 \%$ & $100.0 \%$ \\
\hline \multicolumn{7}{|c|}{ Statistical information of Occupation \& Width of Road and Side walk with physical facilities } \\
\hline \multirow{18}{*}{ Occupation } & & & Width of & f Road and Side & walk & \\
\hline & & & Don't know & Not Satisfied & Satisfied & 10tat \\
\hline & \multirow{2}{*}{ Daily Market } & Count & 0 & 13 & 7 & 20 \\
\hline & & $\%$ within Occupation & $0.0 \%$ & $65.0 \%$ & $35.0 \%$ & $100.0 \%$ \\
\hline & \multirow{2}{*}{ Garments } & Count & 5 & 44 & 13 & 62 \\
\hline & & $\%$ within Occupation & $8.1 \%$ & $71.0 \%$ & $21.0 \%$ & $100.0 \%$ \\
\hline & \multirow{2}{*}{ House Wife } & Count & 1 & 6 & 2 & 9 \\
\hline & & $\%$ within Occupation & $11.1 \%$ & $66.7 \%$ & $22.2 \%$ & $100.0 \%$ \\
\hline & \multirow{2}{*}{ Service } & Count & 0 & 4 & 1 & 5 \\
\hline & & $\%$ within Occupation & $0.0 \%$ & $80.0 \%$ & $20.0 \%$ & $100.0 \%$ \\
\hline & \multirow{2}{*}{ Street Vendor } & Count & 1 & 4 & 1 & 6 \\
\hline & & $\%$ within Occupation & $16.7 \%$ & $66.7 \%$ & $16.7 \%$ & $100.0 \%$ \\
\hline & \multirow{2}{*}{ Student } & Count & 2 & 5 & 3 & 10 \\
\hline & & $\%$ within Occupation & $20.0 \%$ & $50.0 \%$ & $30.0 \%$ & $100.0 \%$ \\
\hline & \multirow{2}{*}{ Wholesale } & Count & 5 & 20 & 6 & 31 \\
\hline & & $\%$ within Occupation & $16.1 \%$ & $64.5 \%$ & $19.4 \%$ & $100.0 \%$ \\
\hline & \multirow{2}{*}{ tal } & Count & 14 & 96 & 33 & 143 \\
\hline & & $\%$ within Occupation & $9.8 \%$ & $67.1 \%$ & $23.1 \%$ & $100.0 \%$ \\
\hline \multicolumn{7}{|c|}{ Statistical information of Occupation \& Air and Noise pollution with physical facilities } \\
\hline & & & \multicolumn{3}{|c|}{ Air and Noise pollution } & \\
\hline & & & Don't know & Not Satisfied & Satisfied & \\
\hline \multirow{12}{*}{ Occupation } & \multirow{2}{*}{ Daily Market } & Count & 0 & 17 & 3 & 20 \\
\hline & & $\%$ within Occupation & $0.0 \%$ & $85.0 \%$ & $15.0 \%$ & $100.0 \%$ \\
\hline & \multirow{2}{*}{ Garments } & Count & 4 & 51 & 7 & 62 \\
\hline & & $\%$ within Occupation & $6.5 \%$ & $82.3 \%$ & $11.3 \%$ & $100.0 \%$ \\
\hline & \multirow{2}{*}{ House Wife } & Count & 1 & 7 & 1 & 9 \\
\hline & & $\%$ within Occupation & $11.1 \%$ & $77.8 \%$ & $11.1 \%$ & $100.0 \%$ \\
\hline & \multirow{2}{*}{ Service } & Count & 1 & 3 & 1 & 5 \\
\hline & & $\%$ within Occupation & $20.0 \%$ & $60.0 \%$ & $20.0 \%$ & $100.0 \%$ \\
\hline & \multirow{2}{*}{ Street Vendor } & Count & 0 & 5 & 1 & 6 \\
\hline & & $\%$ within Occupation & $0.0 \%$ & $83.3 \%$ & $16.7 \%$ & $100.0 \%$ \\
\hline & \multirow{2}{*}{ Student } & Count & 0 & 10 & 0 & 10 \\
\hline & & $\%$ within Occupation & $0.0 \%$ & $100.0 \%$ & $0.0 \%$ & $100.0 \%$ \\
\hline
\end{tabular}




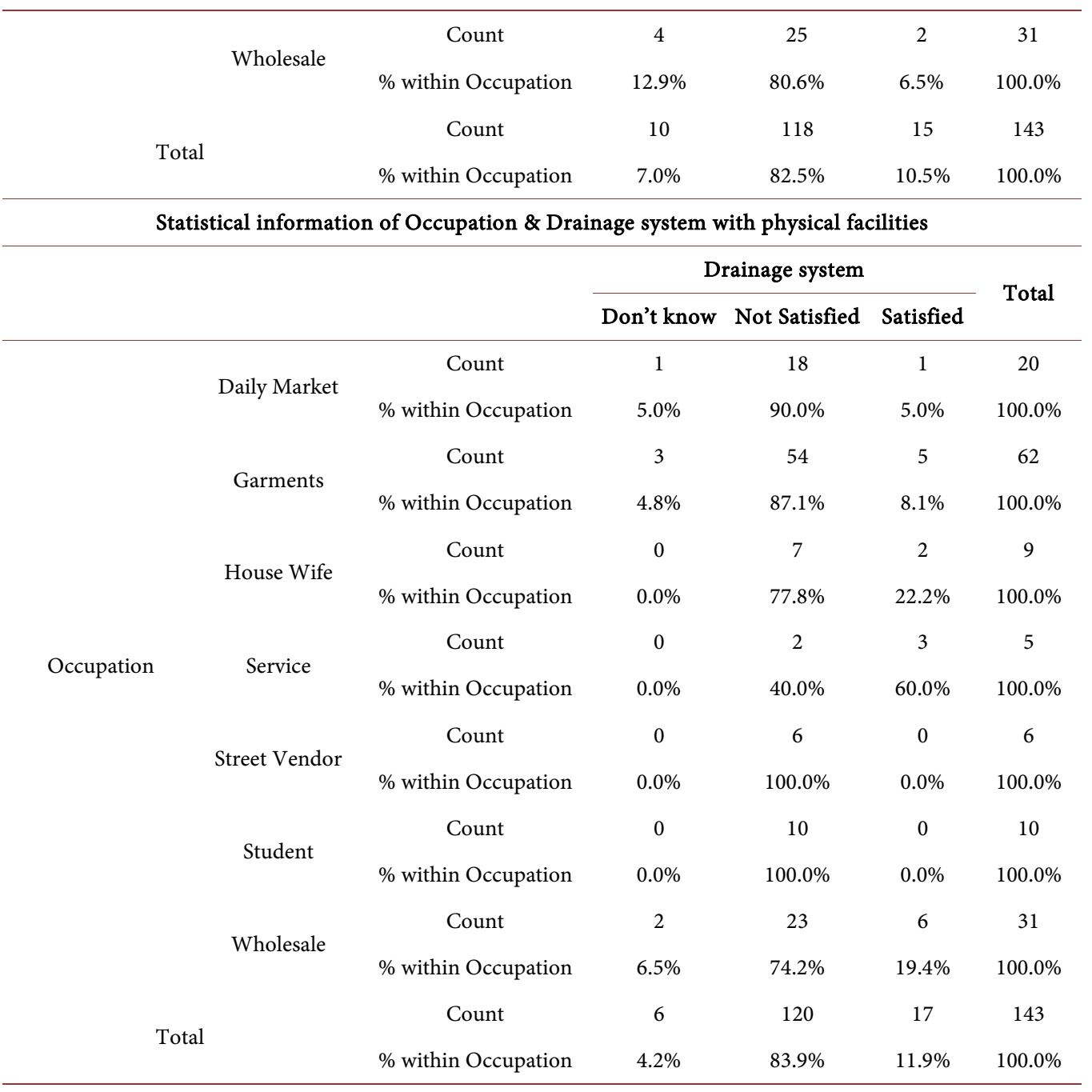

\section{Appendix 2}

Table A2. Statistical information of Occupation \& Employment/Job with economical facilities.

\begin{tabular}{|c|c|c|c|c|c|c|}
\hline \multicolumn{7}{|c|}{ Statistical information of Occupation \& Employment/Job with economical facilities } \\
\hline & & & \multicolumn{3}{|c|}{ Employment/Job } & \multirow{2}{*}{ Total } \\
\hline & & & Don't know & Not Satisfied & Satisfied & \\
\hline \multirow{8}{*}{ Occupation } & \multirow{2}{*}{ Daily Market } & Count & 2 & 4 & 14 & 20 \\
\hline & & $\%$ within Occupation & $10.0 \%$ & $20.0 \%$ & $70.0 \%$ & $100.0 \%$ \\
\hline & \multirow{2}{*}{ Garments } & Count & 4 & 18 & 40 & 62 \\
\hline & & $\%$ within Occupation & $6.5 \%$ & $29.0 \%$ & $64.5 \%$ & $100.0 \%$ \\
\hline & \multirow{2}{*}{ House Wife } & Count & 1 & 5 & 3 & 9 \\
\hline & & $\%$ within Occupation & $11.1 \%$ & $55.6 \%$ & $33.3 \%$ & $100.0 \%$ \\
\hline & \multirow{2}{*}{ Service } & Count & 0 & 3 & 2 & 5 \\
\hline & & $\%$ within Occupation & $0.0 \%$ & $60.0 \%$ & $40.0 \%$ & $100.0 \%$ \\
\hline
\end{tabular}


Md. M. Rahman et al.

\section{Continued}

\begin{tabular}{|c|c|c|c|c|c|c|}
\hline \multirow{2}{*}{\multicolumn{2}{|c|}{ Street Vendor }} & Count & 1 & 2 & 3 & 6 \\
\hline & & $\%$ within Occupation & $16.7 \%$ & $33.3 \%$ & $50.0 \%$ & $100.0 \%$ \\
\hline \multirow{2}{*}{\multicolumn{2}{|c|}{ Student }} & Count & 1 & 4 & 5 & 10 \\
\hline & & $\%$ within Occupation & $10.0 \%$ & $40.0 \%$ & $50.0 \%$ & $100.0 \%$ \\
\hline & \multirow{4}{*}{ Wholesale } & Count & 2 & 9 & 20 & 31 \\
\hline & & $\%$ within Occupation & $6.5 \%$ & $29.0 \%$ & $64.5 \%$ & $100.0 \%$ \\
\hline & & Count & 11 & 45 & 87 & 143 \\
\hline & & $\%$ within Occupation & $7.7 \%$ & $31.5 \%$ & $60.8 \%$ & $100.0 \%$ \\
\hline \multicolumn{7}{|c|}{ Statistical information of Occupation \& Shopping Facilities and Environments with economical facilities } \\
\hline & & & \multicolumn{3}{|c|}{ Shopping Facilities and Environments } & \multirow{2}{*}{ Total } \\
\hline & & & Don't know & Not Satisfied & Satisfied & \\
\hline \multirow{3}{*}{\multicolumn{2}{|c|}{ Daily Market }} & Count & 0 & 5 & 15 & 20 \\
\hline & & $\%$ within Occupation & $0.0 \%$ & $25.0 \%$ & $75.0 \%$ & $100.0 \%$ \\
\hline & & Count & 1 & 15 & 46 & 62 \\
\hline \multicolumn{2}{|r|}{ Garments } & $\%$ within Occupation & $1.6 \%$ & $24.2 \%$ & $74.2 \%$ & $100.0 \%$ \\
\hline \multirow{2}{*}{\multicolumn{2}{|c|}{ House Wife }} & Count & 1 & 2 & 6 & 9 \\
\hline & & $\%$ within Occupation & $11.1 \%$ & $22.2 \%$ & $66.7 \%$ & $100.0 \%$ \\
\hline \multirow{8}{*}{ Occupation } & \multirow{2}{*}{ Service } & Count & 1 & 0 & 4 & 5 \\
\hline & & $\%$ within Occupation & $20.0 \%$ & $0.0 \%$ & $80.0 \%$ & $100.0 \%$ \\
\hline & \multirow{2}{*}{ Street Vendor } & Count & 0 & 2 & 4 & 6 \\
\hline & & $\%$ within Occupation & $0.0 \%$ & $33.3 \%$ & $66.7 \%$ & $100.0 \%$ \\
\hline & \multirow{2}{*}{ Student } & Count & 0 & 5 & 5 & 10 \\
\hline & & $\%$ within Occupation & $0.0 \%$ & $50.0 \%$ & $50.0 \%$ & $100.0 \%$ \\
\hline & \multirow{2}{*}{ Wholesale } & Count & 1 & 6 & 24 & 31 \\
\hline & & $\%$ within Occupation & $3.2 \%$ & $19.4 \%$ & $77.4 \%$ & $100.0 \%$ \\
\hline \multirow{2}{*}{\multicolumn{2}{|c|}{ Total }} & Count & 4 & 35 & 104 & 143 \\
\hline & & $\%$ within Occupation & $2.8 \%$ & $24.5 \%$ & $72.7 \%$ & $100.0 \%$ \\
\hline
\end{tabular}

\section{Appendix 3}

Table A3. Statistical information of Occupation and Accessibilities with social facilities.

\begin{tabular}{|c|c|c|c|c|c|c|}
\hline \multicolumn{7}{|c|}{ Statistical information of Occupation and Accessibilities with social facilities } \\
\hline & & & \multicolumn{3}{|c|}{$\begin{array}{l}\text { Accessibilities-hospitals, bazaar, } \\
\text { services, schools/college }\end{array}$} & \multirow[t]{2}{*}{ Total } \\
\hline & & & Don't know & Not Satisfied & Satisfied & \\
\hline \multirow{3}{*}{ Occupation } & & Count & 0 & 6 & 14 & 20 \\
\hline & Daily Market & $\%$ within Occupation & $0.0 \%$ & $30.0 \%$ & $70.0 \%$ & $100.0 \%$ \\
\hline & Garments & Count & 2 & 29 & 31 & 62 \\
\hline
\end{tabular}




\begin{tabular}{|c|c|c|c|c|c|c|}
\hline & & $\%$ within Occupation & $3.2 \%$ & $46.8 \%$ & $50.0 \%$ & $100.0 \%$ \\
\hline \multirow{2}{*}{\multicolumn{2}{|c|}{ House Wife }} & Count & 1 & 2 & 6 & 9 \\
\hline & & $\%$ within Occupation & $11.1 \%$ & $22.2 \%$ & $66.7 \%$ & $100.0 \%$ \\
\hline \multirow{2}{*}{\multicolumn{2}{|c|}{ Service }} & Count & 0 & 4 & 1 & 5 \\
\hline & & $\%$ within Occupation & $0.0 \%$ & $80.0 \%$ & $20.0 \%$ & $100.0 \%$ \\
\hline \multirow{2}{*}{\multicolumn{2}{|c|}{ Street Vendor }} & Count & 0 & 2 & 4 & 6 \\
\hline & & $\%$ within Occupation & $0.0 \%$ & $33.3 \%$ & $66.7 \%$ & $100.0 \%$ \\
\hline \multirow{2}{*}{\multicolumn{2}{|c|}{ Student }} & Count & 0 & 4 & 6 & 10 \\
\hline & & $\%$ within Occupation & $0.0 \%$ & $40.0 \%$ & $60.0 \%$ & $100.0 \%$ \\
\hline \multirow{4}{*}{\multicolumn{2}{|c|}{ Wholesale }} & Count & 1 & 16 & 14 & 31 \\
\hline & & $\%$ within Occupation & $3.2 \%$ & $51.6 \%$ & $45.2 \%$ & $100.0 \%$ \\
\hline & & Count & 4 & 63 & 76 & 143 \\
\hline & & $\%$ within Occupation & $2.8 \%$ & $44.1 \%$ & $53.1 \%$ & $100.0 \%$ \\
\hline \multicolumn{7}{|c|}{ Statistical information of Occupation \& Recreation Facilities and Public spaces with social facilities } \\
\hline & & & \multicolumn{3}{|c|}{ Recreation Facilities and Public spaces } & \multirow{2}{*}{ Total } \\
\hline & & & Don't know & Not Satisfied & Satisfied & \\
\hline \multirow{16}{*}{ Occupation } & \multirow{2}{*}{ Daily Market } & Count & 0 & 17 & 3 & 20 \\
\hline & & $\%$ within Occupation & $0.0 \%$ & $85.0 \%$ & $15.0 \%$ & $100.0 \%$ \\
\hline & \multirow{2}{*}{ Garments } & Count & 3 & 47 & 12 & 62 \\
\hline & & $\%$ within Occupation & $4.8 \%$ & $75.8 \%$ & $19.4 \%$ & $100.0 \%$ \\
\hline & \multirow{2}{*}{ House Wife } & Count & 0 & 9 & 0 & 9 \\
\hline & & $\%$ within Occupation & $0.0 \%$ & $100.0 \%$ & $0.0 \%$ & $100.0 \%$ \\
\hline & \multirow{2}{*}{ Service } & Count & 1 & 3 & 1 & 5 \\
\hline & & $\%$ within Occupation & $20.0 \%$ & $60.0 \%$ & $20.0 \%$ & $100.0 \%$ \\
\hline & \multirow{2}{*}{ Street Vendor } & Count & 1 & 4 & 1 & 6 \\
\hline & & $\%$ within Occupation & $16.7 \%$ & $66.7 \%$ & $16.7 \%$ & $100.0 \%$ \\
\hline & \multirow{2}{*}{ Student } & Count & 1 & 7 & 2 & 10 \\
\hline & & $\%$ within Occupation & $10.0 \%$ & $70.0 \%$ & $20.0 \%$ & $100.0 \%$ \\
\hline & \multirow{2}{*}{ Wholesale } & Count & 1 & 28 & 2 & 31 \\
\hline & & $\%$ within Occupation & $3.2 \%$ & $90.3 \%$ & $6.5 \%$ & $100.0 \%$ \\
\hline & \multirow{2}{*}{ tal } & Count & 7 & 115 & 21 & 143 \\
\hline & & $\%$ within Occupation & $4.9 \%$ & $80.4 \%$ & $14.7 \%$ & $100.0 \%$ \\
\hline
\end{tabular}

